\title{
THE SUNDEW HYBRID DROSERA XBELEZIANA FOUND ON LONG ISLAND, NEW YORK
}

\section{MATTHEW M. KAELIN • Bellmore • New York•USA・mattfromquogue@aol.com}

Long Island, New York is the largest and most populated island in the contiguous United States and was formed by glacial terminal moraines and outwash plains which created many unique ecosystems. Home to sixteen species of carnivorous plants, there are three sundew species that are native of which Drosera filiformis are quite unmistakable with their long, threadlike leaves that grow erect. The other two species, $D$. rotundifolia and $D$. intermedia, normally grow as rosettes and appear to be quite similar to one another, but can be differentiated by a few notable characteristics.

Drosera rotundifolia grow as low rosettes having nearly circular traps that are wider than they are tall with petioles that tend to be slightly flattened, creased at their edges and have varying degrees of bristles (Fig. 1). The crown (central rosette, which consists of developing leaves) is wide and hairy with bristles. Drosera rotundifolia are quite common in the northern latitudes throughout the world and are readily found on Long Island. They normally grow in live Sphagnum moss, peaty soil, or even sandy peat, all usually moist, but tend to not be exceedingly wet. They have been found on Long Island in Sphagnum bogs, on kettle hole pond shores, along consistently wet sandy trails, and even in the Sphagnum moss surrounding a fresh-water aquifer among the desert-like dunes of the Fire Island wilderness.

Drosera intermedia can be identified by their traps (Fig. 1). Appearing more spoon-like, they are taller and much narrower than the D. rotundifolia traps. The petioles are smooth, rounded, and tend to be long. The crown is smaller and narrower than D. rotundifolia and does not have as hairy of bristles. Some $D$. intermedia may form long stalks in response to seasonal flooding and can grow rather large. Drosera intermedia can be found growing in sandy soils that are very wet and may be partially under water, such as along kettle hole pond and vernal pond shores, in and around any ditches or puddles that are near the water table, and have even been found growing in a low, wet depression near the fresh water aquifer in the dunes of the Fire Island wilderness. They can also be
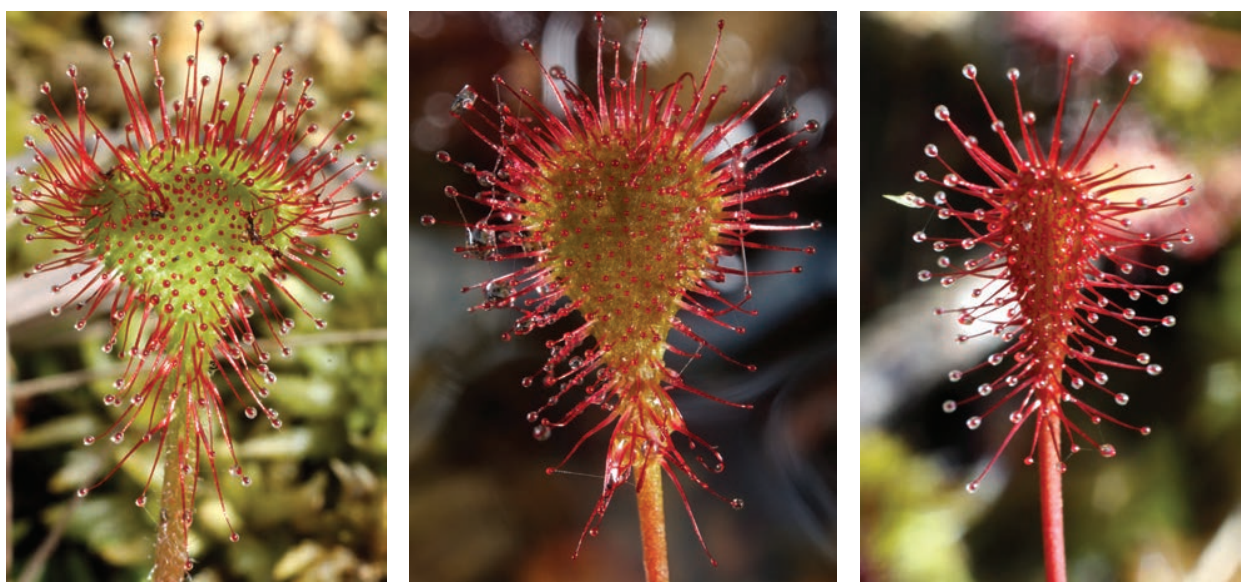

Figure 1: Drosera rotundifolia (left), D. × beleziana (center), and D. intermedia (right) traps. The center photo was taken in the Wharton State Forest, New Jersey, courtesy of Jason Ksepka. 

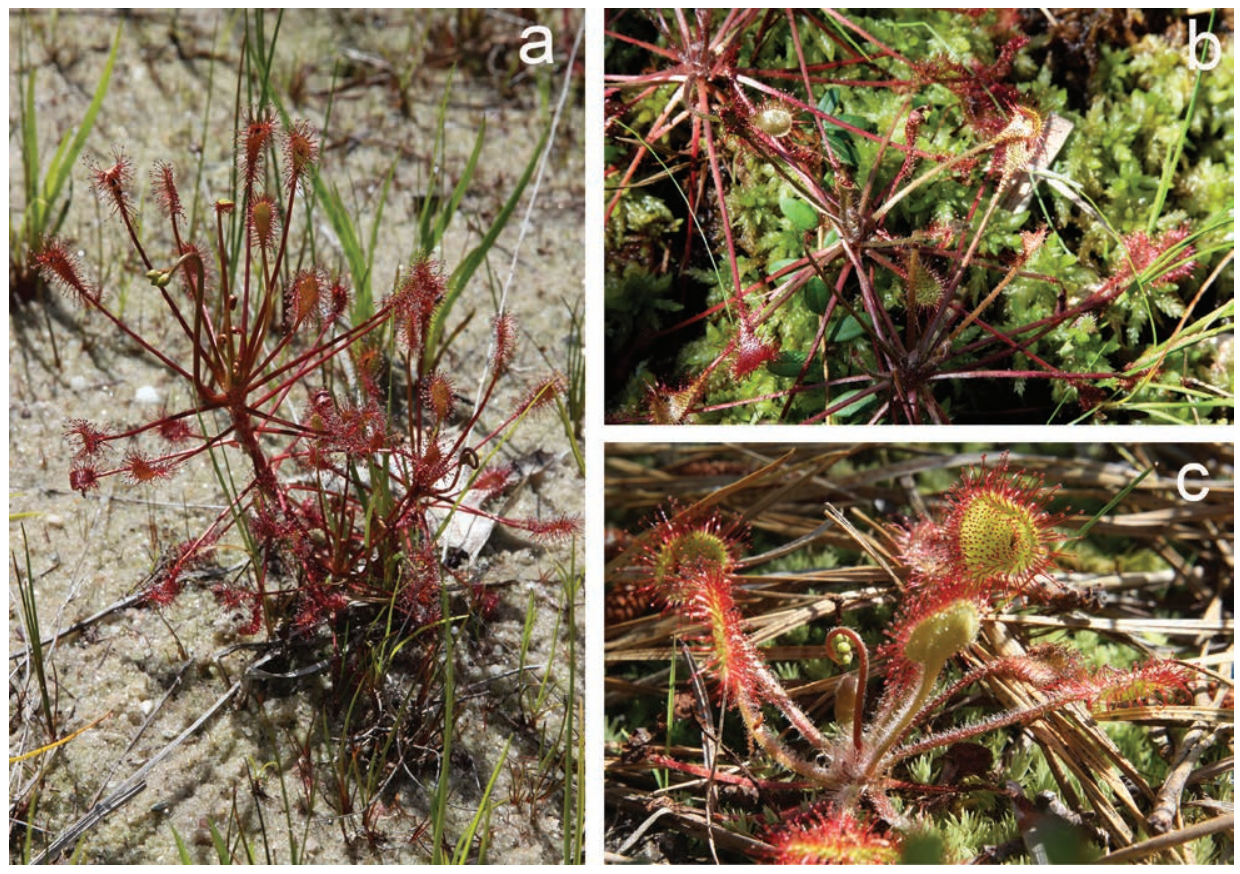

Figure 2: a) Drosera intermedia plant exhibiting characteristic smooth petioles and narrow crown with spoon-shaped traps growing in damp sand at edge of a vernal pond shore. Plant has grown into a stalk from earlier seasonal flooding which has subsided and is richly colored from exposure to full sun.

b) Drosera $\times$ beleziana plant showing identifying characteristics such as long, rounded petioles with bristles and a wide, bristled crown. Traps are of intermediate shape between the two parents. Numerous examples of both parent species were found nearby.

c) Drosera rotundifolia plant exhibiting characteristic heavily bristled petioles and wide crown with round-shaped traps. Plant is growing in barely damp sand along a historic colonial wagon-trail in Pine Barren habitat which dips near the water table and contains the biodiversity of a coastal plains pond.

seen growing in more peaty soils, in the live moss of Sphagnum bogs, and in the muck surrounding those bogs.

The hybrid between D. rotundifolia and D. intermedia is known as Drosera $\times$ beleziana (Fig. 1). I have recently discovered these hybrid plants on Long Island for the first time in New York. They were growing in the live Sphagnum moss hummocks in an Atlantic White Cedar forest on the edge of a pond which has moving water slowly flowing through it as part of the Peconic River watershed, and was once home to a commercial Cranberry bog. So far, I have only observed this hybrid growing in live Sphagnum moss in the wild, but cultivated specimens grow in a wet peat/sand mix quite well.

Drosera $\times$ beleziana can grow noticeably large compared to either of the parents, but can be difficult to identify because the hybrid contains characteristics from both. Of the recent specimens found on Long Island, the discerning characteristics of some $D$. ×beleziana are the wide crown shape heavy with bristles and the hairy petioles that $D$. rotundifolia exhibit combined with the long and rounded petioles of $D$. intermedia. The trap shapes are intermediate between both parents and 
in these examples, look more like $D$. intermedia. In other cases, $D$. $\times$ beleziana can appear to be the opposite, with wider more $D$. rotundifolia-like traps combined with the smoother petioles and the smaller crown of $D$. intermedia. These traits seem to vary with the individual, but most visible features are a blending of the characteristics of each parent, not fully being one or the other. Any of these characteristics are less noticeable with young plants, being more easily identified in more mature and fully grown plants.

Drosera $\times$ beleziana has not been commonly identified in the wild, perhaps because it takes careful observation to see the intermediate characteristics — or, perhaps, hybridization may be rare. The flowers of both of the parents have somewhat dissimilar shapes and sizes, although the differences are not all that extreme. The flowers open at similar times of the year and day, and it would be interesting to study the pollinators of each of these species. It is possible that the variability observed in the hybrids may depend on whether $D$. rotundifolia or D. intermedia is the pollen parent.

Drosera $\times$ beleziana has been reported from France, England, Scandinavia, Massachusetts, the New Jersey Pine Barrens, and now the Long Island Pine Barrens. There is no reason this hybrid should not be more commonly found in areas where both parent species grow together other than the ease of them being overlooked, misidentified, or confused with either of the parents. Perhaps with more understanding of the characteristics, this hybrid will become more readily identified in the other areas of the world where both of the parent species coexist.

Further reading:

Schnell, D.E. 1976. Carnivorous Plants of the United States and Canada. J.F. Blair, Winston-Salem, NC.

McPherson, S., and Schnell, D. 2013. Field Guide to the Carnivorous Plants of the United States and

Canada. Redfern Natural History Productions Ltd., Poole, UK.

http://www.carnivorousplants.org/cpn/articles/CPNv07n4p107_109.pdf

http://carnivorousplantsocietyblog.blogspot.com/2012/09/d-beleziana.html

http://www.biodiversitylibrary.org/item/22090\#page/208/mode/1up

http://www.carnivorousplants.org/cp/DroseraHybrids.php

http://www.sarracenia.com/faq/faq5265.html

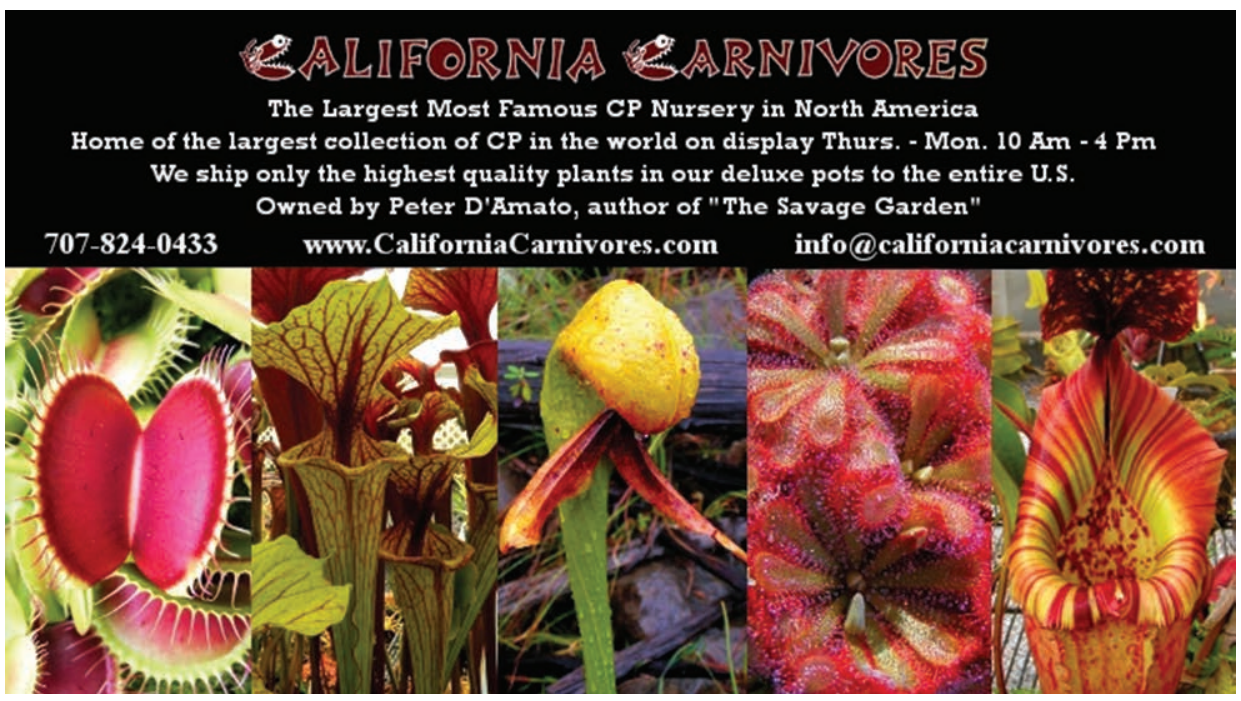

